\title{
The Role of Non-Governmental Organisations (NGOs) in Community- based Mental Health Services in Northern Nigeria: Prospects and Challenges
}

\author{
Anyebe, E.E..$^{*}$, Abubakar, F.U. ${ }^{2}$, Garba, S.N. ${ }^{3}$, Murtala, H.H ${ }^{3}$, Igbinlade, A.S ${ }^{4}$ \\ ${ }^{1}$ Department of Nursing Sciences, Faculty of Clinical Sciences, College of Health Sciences, \\ University of Ilorin, Ilorin, Kwara State Nigeria \\ ${ }^{2}$ Office of the Registrar/Secretary-General, Nursing and Midwifery Council of Nigeria, Abuja \\ ${ }^{3}$ Department of Nursing Sciences, Faculty of Allied Health Sciences, College of Health \\ Sciences, BUK, Kano \\ ${ }^{4}$ Department of Nursing Sciences, National Open University of Nigeria, Abuja
}

\begin{abstract}
Despite the role of non-governmental organisations (NGOs) in many health issues, their role in community mental health services in parts of northern Nigeria is unknown. This study explored the availability and role of NGOs in community-mental health care services, with a view to identifying the prospects and challenges. Using the convergent mixed methods approach, a self-constructed questionnaire and in-depth interviews were used to collect data from 205 conveniently and purposively selected study participants. Descriptive and thematic analyses were done and then triangulated to meet research objectives. There is a scarcity of mental health-related NGOs in the study areas; only one NGO engaged in the mental health activities was identified (13.4\%). Surprisingly attempts by the only available NGO at providing the needed community-based mental health care were "frustrated" by certain government policy directions, which appear to paralyse activities and intentions of the only existing one. NGOs for mental health care are lacking. There is a dire need for NGO activities in mental health care. Efforts should be made to attract NGOs to the study areas in view of the increasing burden of mental health issues in the communities in the setting. Governments at all levels, community-based organisations and traditional institutions can be instrumental to this. NGOs within and outside the study areas focusing on community health in general and mental health care, in particular, may also interrogate this situation further for urgent intervention.
\end{abstract}

Keywords: Community mental health care, Collaboration, NGOs, Northern Nigeria.

\section{Introduction}

Mental health care has, for many decades, been low in the priority list of health policymakers at all levels in Nigeria [1, 2, 3], with wide intervention gaps despite the 20 to 30 percent of its 200 million population suffering from mental disorders, with rising cases of suicide $[4,5]$. Challenges facing the country in terms of mental health care include inadequate human resources, paltry budget allocation, and lack of deliberate policy on mental health [6,7]. Consequently, many mental health problems exist (and loom) in all communities in the country $[8,9,2,10]$.

The role of multisectoral collaboration to address mental health services worldwide has been the focus of many operational designs [11, 2], encouraging NGOs to assist in the promotion of mental health care, particularly the preventive and rehabilitative aspects. These efforts have been observed in India [12]. Many 
non-governmental organisations (NGOs) are working to improve health care and fill the gaps $[13,14]$ in specific areas of need. The role of NGOs in health care like in maternal, newborn (neonatal) and child health $(\mathrm{MNCH})$ care are well documented [15, 16]. High maternal and child morbidity and mortality rates have been reduced significantly in India, Canada, and Nigeria by activities of many NGOs $[17,14,13$, $18]$.

In Nigeria, there are very limited NGOs focusing on mental health services, training, and research as well as policies [16] due to governmental policy on mental health $[19,2]$. In Nigeria, Lagos State appears to attract most of the few of mental health NGOs [20, 21]. In northern Nigeria, only a few NGOs focusing on mental health sprang up in Borno State recently to help those traumatised by Boko Haram [22, 23].

However, the role of NGOs in community mental health care in northern Nigeria at the primary healthcare level sparingly attracts the attention of researchers. The study explored the availability and role of NGOs in the provision of community-based mental health care services in three States in northern Nigeria.

\section{Methods and Materials}

\section{Study Design and Setting}

This community-based exploratory and cross-sectional study adopted mixed methods to explore the availability of NGOs and their involvement in mental health activities. The study is part of a larger study in three purposively selected States from north-central, northwest, and northeast Nigeria on mental health services. PHCs (and host communities) were then randomly selected.

\section{Study Participants and Sampling}

As shown in Table 1, a total of 205 participants were involved in the study. This consisted of a convenient sample of 191 primary health care professionals from 47 randomly selected primary healthcare centres in three states. They were selected from their centres based on their availability at the time of visit. They constituted the respondents for the survey questionnaire.

Table 1. Study Participants

\begin{tabular}{|l|l|l|l|l|l|}
\hline SN & Study participant category & Benue & Kaduna & Gombe & Total \\
\hline 1 & Primary care professionals for survey & 58 & 67 & 66 & 191 \\
\hline 2 & IDI participants & 4 & 3 & 4 & 11 \\
\hline 3 & Trainee volunteers (Trained Nurses) & 1 & 1 & 0 & 2 \\
\hline 4 & NGO staff & 1 & 0 & 0 & 1 \\
\hline \multicolumn{2}{|l}{ Total } & $\mathbf{6 3}$ & $\mathbf{7 1}$ & $\mathbf{7 0}$ & $\mathbf{2 0 5}$ \\
\hline
\end{tabular}

In addition, a purposive sample of 11 primary health care coordinators/managers was selected based on their strategic position. Similarly, two trained volunteers sponsored by an NGO were identified in two states (Benue and Kaduna) and selected to explore their experiences.

They were part of a batch of five nurses trained by an NGO as mental health psychiatric nurses. A staff of the NGO was also purposively selected to elicit information on the NGO's activities for mental health.

\section{Instruments for Data Collection}

A survey questionnaire and two different IDI Guides for primary health care coordinators/managers and for the two trained volunteers were used to collect both quantitative (through questionnaire) and qualitative (via IDIs) data.

The survey questionnaire is a selfconstructed-item instrument in two sections: Section A on Socio-demographic characteristics, Section B consisted of eight items including: "Are you aware of any new 
mental health $\mathrm{NGO}$ in PHC or community settings?" "If yes, list these such NGOs"; "If available whether local or national or international NGO"; "focus of their services"; "whether these services (either as pilots or scaled) have been formally evaluated"; whether such NGOs are encouraged in the provision of mental health care services in my centre" and "if there exists any collaboration between the government with non-governmental organizations."

In-depth interview (IDI) Guides for primary health care coordinators/managers and trained CBM volunteers explored their views on mental health NGOs in the study settings, the experiences of the trainees of an NGO in relation to governmental commitment. The IDI guides had open-ended questions to probe the existence of NGOs, their mission statement, their activities, their relationship with relevant organs of government and the challenges or otherwise of the activities.

The tools were validated by a panel of five experts (professional and academic) in mental health. The reliability of the questionnaire was ascertained by Cronbach's coefficient of 0.78 .

\section{Procedure for Data Collection}

With the help of research assistants, data were collected between December 2015 and June 2016 in the three states. The questionnaires were both self-administered and interviewer-administered (for some PHC workers who could not comfortably fill in the questionnaires). Although the PHC professionals had a minimum of a diploma, many were not comfortable filling in the questionnaire. All the questionnaires were retrieved on each day of administration; the response rate was $100 \%$.

The IDIs for PHC coordinators and managers at the Local Government levels were conducted by the principal investigator (first author) at the centres in their offices. Each interview lasted for between 30 to 45 minutes.
The interviews were all audio-recorded, and field notes were also taken.

The trained nurses (volunteers) were also interviewed in a similar way but in their homes; one in Makurdi, Benue State and the other in Kaduna. Although they were all trained by an NGO in Benue State, they would not be employed and involved in the community mental health services as already planned due to the embargo on employment.

\section{Data Analysis}

Data cleaning, editing, and coding were done. The IDI participants were coded: $\mathrm{C} 1-\mathrm{C} 3$ for CBM trainees and staff; B1 - B4 for Benue IDI participants, K1 - K3 for Kaduna and G1 G4 for Gombe (Appendix I).

Quantitative data were coded and analysed using SPSS Version 23. The qualitative data were transcribed, thematically analysed, categorized, coded, and presented using narratives and verbatim quotes.

The two strands of data (quantitative and qualitative) were synergised to meet the research objectives:

1. The role of the NGOs.

2. The Challenges.

3. The Prospects/Opportunities.

\section{Ethical Consideration}

Institutional approval for the study was obtained (Ethical Clearance Certificate No: ABUTH/HREC/K028/2014). The Individual States and study participants also gave permissions and consents, respectively.

\section{Results}

\section{Socio-demographic Characteristics of Study Participants}

As shown in Table 2, study participants' ages range from 23 to 62 years, with a mean age of 35.5 years. They are predominantly married (75.4\%), Christians (61.8\%) female (55.6\%), Hausa (21.5\%). 
Table 2. PHC workers' Socio-demographic Characteristics

\begin{tabular}{|c|c|c|c|}
\hline S/No & Variable & Frequency & Percentage \\
\hline \multirow[t]{6}{*}{1.} & \multicolumn{3}{|l|}{ Age (in years) } \\
\hline & $20-39$ & 133 & 69.6 \\
\hline & $40-59$ & 54 & 28.3 \\
\hline & 60 and above & 1 & 0.5 \\
\hline & No Response & 3 & 1.6 \\
\hline & Total & 191 & 100.0 \\
\hline \multirow[t]{5}{*}{2} & \multicolumn{3}{|l|}{ Gender } \\
\hline & Male & 84 & 44.0 \\
\hline & Female & 106 & 55.5 \\
\hline & No Response & 1 & 0.5 \\
\hline & Total & 191 & 100.0 \\
\hline \multirow[t]{10}{*}{3} & \multicolumn{3}{|l|}{ Ethnic groups } \\
\hline & Hausa & 41 & 21.5 \\
\hline & Fulani & 15 & 7.9 \\
\hline & Gombe Ethnic Groups & 14 & 7.3 \\
\hline & Idoma & 33 & 17.3 \\
\hline & Tiv & 24 & 12.6 \\
\hline & Southern Ethnic Groups & 27 & 14.1 \\
\hline & Others & 35 & 18.3 \\
\hline & No Response & 2 & 1.0 \\
\hline & Total & 191 & 100.0 \\
\hline \multirow[t]{4}{*}{4} & \multicolumn{3}{|l|}{ Religion } \\
\hline & Christianity & 118 & 61.8 \\
\hline & Islam & 73 & 38.2 \\
\hline & Total & 191 & 100.0 \\
\hline \multirow[t]{6}{*}{5} & \multicolumn{3}{|l|}{ Marital status } \\
\hline & Single & 43 & 22.5 \\
\hline & Married & 144 & 75.4 \\
\hline & Widow(er) & 2 & 1.0 \\
\hline & No Response & 2 & 1.0 \\
\hline & Total & 191 & 100.0 \\
\hline
\end{tabular}

Mean age: 35.5 years

\section{Availability of NGO in Mental Health in the Community}

In the survey, primary healthcare workers were asked to indicate if they were aware of any NGO working on mental health in their community in the last five years. Their responses are shown in Figure 1. 


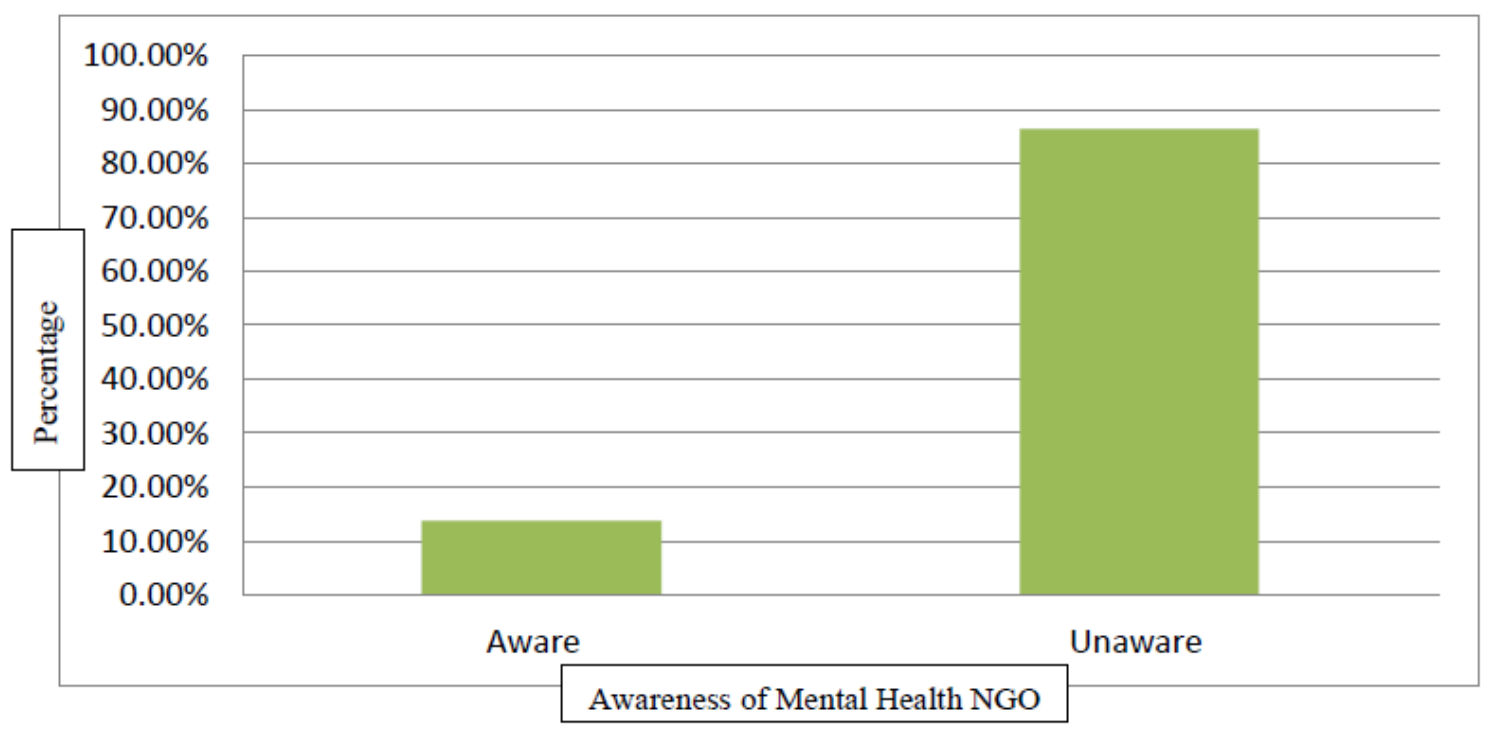

Figure. 1. Respondents' Awareness of NGOs on Mental Health in Study Settings

A majority (86.4\%) were not aware of any NGO related to mental health; only $13.6 \%$ $(n=26)$ of them claimed to be aware of the existence of such NGOs.

Among those who claimed to be aware $(\mathrm{N}=26)$, only $8(30.8 \%)$ of them were able to identify the NGOs they claimed to be aware of.
The responses of the eight of them are shown in Table 3 according to their study sites. In the Table, only respondents from Benue identified an NGO involved in mental health care in three Local Government Areas (LGAs). Gombe and Kaduna States had no record of any known mental health-related NGO.

Table 3. PHC workers' Opinions on Availability of NGOs for CMHC* by Study sites

\begin{tabular}{|l|l|l|l|l|}
\hline \multirow{2}{*}{ State } & \multirow{2}{*}{ LGA } & \multicolumn{2}{|l|}{ NGOs for CMHC* } & \multirow{2}{*}{ Total } \\
\cline { 3 - 5 } & & Yes & No & \\
\hline \multirow{3}{*}{ Benue } & Makurdi & 3 & 17 & 20 \\
\cline { 2 - 5 } & Vandeikya & 1 & 15 & 16 \\
\cline { 2 - 5 } & Otukpo & 4 & 26 & 30 \\
\hline \multirow{3}{*}{ Kaduna } & Giwa & 0 & 27 & 27 \\
\cline { 2 - 5 } & Kaduna South & 0 & 20 & 20 \\
\cline { 2 - 5 } & Kachia & 0 & 20 & 20 \\
\hline \multirow{3}{*}{ Gombe } & Gombe & 0 & 21 & 21 \\
\cline { 2 - 5 } & Yamaltu-Deba & 0 & 22 & 22 \\
\cline { 2 - 5 } & Kaltungo & 0 & 15 & 15 \\
\hline \multirow{2}{*}{ Total (\%) } & $\mathbf{8}(\mathbf{4 . 2})$ & $\mathbf{1 8 3}(\mathbf{9 5 . 8 )}$ & $\mathbf{1 9 1}(\mathbf{1 0 0 . 0})$ \\
\hline
\end{tabular}

Source: Crosstab of NGO for CMHC and LGAs, Field data 2015.

*Community mental health care.

The survey respondents, when asked level of collaboration and encouragement NGOs with the relevant government in providing services in their centres, more than half of the workers $(52.4 \% ; \mathrm{n}=100)$ said no; another $45(23.6 \%)$ of them were not sure (Figure 2). 


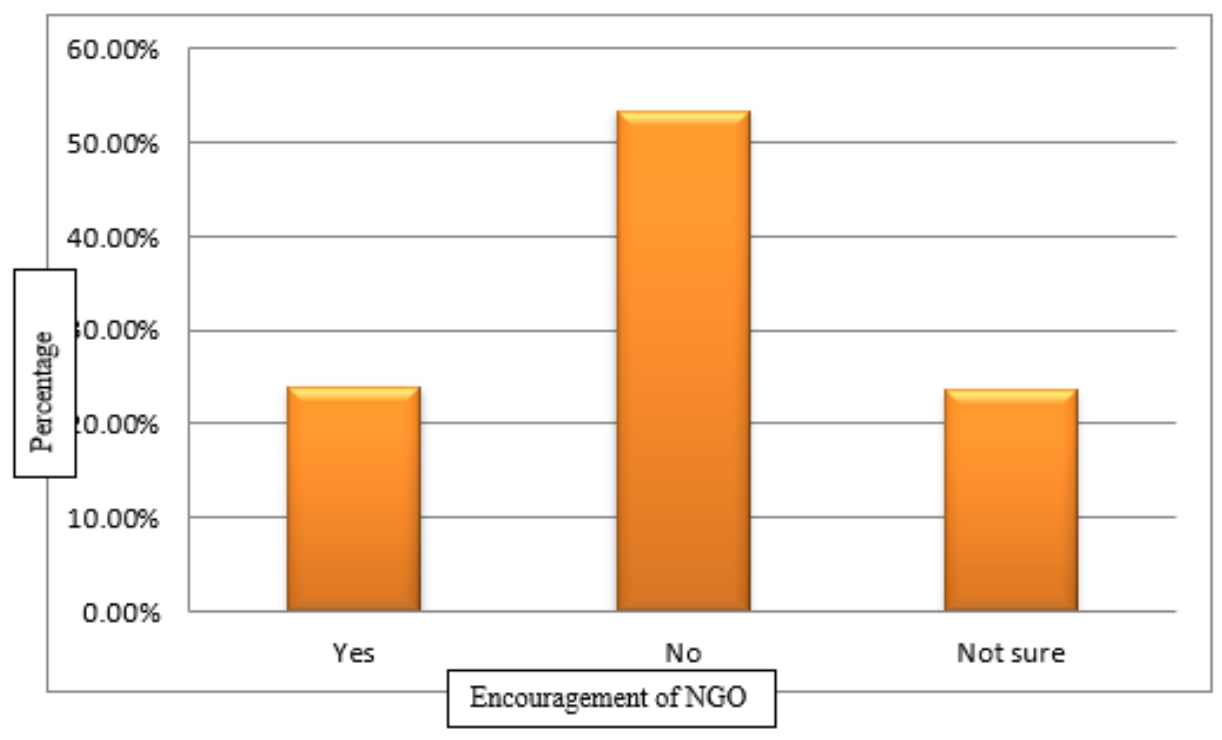

Figure 2. Government's Encouragement of NGO involvement in Mental Health Care

This set of data was explored further from health administrators, staff and trained volunteers of an NGO and a community psychiatrist in the States. During in-depth interviews, it was established that no other NGO could be identified in the two States. Health administrators in these States decried the absence of NGOs in their States. In one of the States, some health administrators said that State deliberately discouraged NGOs in mental health from operating due to some past experiences shared by the health administrators. For instance, at one of the LGAs in Kaduna State, the PHC coordinator said that she discouraged attempts by some would-be NGOs that approached the LGA to assist in providing some mental health services because previously "some fake NGOs extorting money from people once existed, so I refused to accept any now" (K1).

A senior consultant in community psychiatry working in a tertiary mental facility, when asked about the availability of any NGO focusing on mental health in the State, exclaimed:

aah...not really... strictly speaking, no NGO dedicated to mental health as such. not strictly, but we have Autism Prevention Group, religious groups such as some Reverend Sisters who have an organized group where they see children with special needs. However, we have seen many organized NGOs like the ones on maternal mortality, HIV, family health, there is no such as far as mental health is concerned (K2).

A similar scenario in Gombe State exists. In Gombe State, the informant from the State PHC Development Agency acknowledged the nonexistence of mental health NGOs, but unlike the informant in the other State, they were expecting such. As he put it: "No NGO yet, but we are ready to work with them" (G1).

\section{Activities of the Existing Non- governmental Organisation (NGO) in Mental Health Care}

The existence of one mental health-related NGO in Benue State was acknowledged by PHC administrators even outside the State. Administrators in Gombe and Kaduna States commended the situation in Benue State, as attested to by a PHC coordinator in Kaduna:

Benue State has started because the Benue State government sent people to Barnawa (i.e., School of Post-basic Psychiatric Nursing, Federal Neuro-psychiatric Hospital) here in 
Kaduna for training. I learnt that one NGO is helping to train nurses there. I even assisted them (the trainees) by introducing them to the community leaders here when they were doing the research project, but in Kaduna here, no such thing (K2).

Even in Gombe State, the presence of a Mental Health NGO in Benue State is common knowledge, as one of the PHC coordinators also affirms that:

In the north, I am not aware of any organised NGO for mental health care apart from one in Benue State, called CBM (Christofoel Blind Mission); although I don't know the detailed activities of the organisation (G3).

During the interview, a staff of Christofoel Blind Mission (CBM) outlined the mission of the NGO as "community mobilization, sensitization and education are their main activities" (C3). At the CBM Headquarters, the key staff listed their main activities and the roles in relation to mental health as follows:

1. Training Nurses for Comprehensive Community Mental Health Programme for Benue State.

2. Provide a comprehensive community mental health programme.

3. Giving periodic lectures on Community Mental Health Programme to Community Health Extension Workers (CHEWs) at the College of Health Technology, Otukpo.

$\mathrm{He}$ narrated the starting point to be the training of mental health personnel, where their focus for the moment was nurses who would work on the programme.

\section{Training of Nurses for Mental Health}

During the interview, the staff explained how the nurses were recruited for training.

The CBM scouted for nurses who are qualified to be trained, but it was difficult to get such because of the $O^{\prime} L$ requirements. However, some nurses were selected from some local government areas and freshers from school. About 12 or so of them were trained, but the Benue state government cannot absorb them because of an embargo on employment (C3).

The nurses who benefitted from the training programmes confirmed the role of the NGO in their training Participants enumerated the role of the CBM in the Benue State. They reported that the NGO had trained two sets of nurses for the programme: the first set of six nurses and the second set five. This was confirmed by the CBM staff and the health administrators in Benue State.

All the PHC coordinators also confirmed this role played by the CBM in the training of the selected nurses, as captured by one of them who said:

They are involved in the training of nurses in Mental Health for the Comprehensive Community Mental Health Programme for Benue State. They train nurses for Benue State to employ. The essence is (that) they will come back and be engaged by the government (B1).

The sponsorship for the training was full, with payment of the entire tuition fees for the duration of the training (18 months) and monthly stipends. The beneficiaries explained that the CBM screened and selected:

Freshly graduate from School of Nursing, and then trained them in mental health. After the training, we would work with them (CBM) at the Local Government in Benue State for two years $(\mathrm{C} 1)$.

For the period of two years, we were paid a stipend of twenty thousand naira (N20, 000.00) every month throughout the training and all our school fees were paid $(\mathrm{C} 2)$.

On the other roles highlighted by the NGO, such as periodic lectures and community mental health education, a health coordinator testified:

The NGO also periodically organises lectures for Community Health Extension Workers (the students in training at the College of Health Technology. They (CBM) also provide logistics for services (i.e., community mental health services) (B3). 
Narratives from the personnel of the NGO, trained nurses and health administrators confirmed the roles being played by the CBM. Both the health and the trained nurses also confirmed that CBM is the only functional mental health-related NGO in the State. As one trained nurse captured it: "It is limited, but CBM exits only in Benue State for now."

\section{Prospects for Providing Mental Health Care}

There are strong indications for functional services from the CBM. The prospects can be discussed under three sub-themes, viz:

1. The commitment of the NGO.

2. A memorandum of understanding.

3. Willingness of the CBM-sponsored nurses to provide community mental health care.

\section{The Existence and Commitment of CBM}

The PI elicited information on the NGO from the PHC Director of Local Government Service Commission of the host State, a staff of the NGO, and two of the nurses who benefitted from the CBM-sponsored training. During indepth interviews with the State Director, he reaffirmed the existence of the CBM in the State and the role the NGO was playing in helping the State to provide mental health services. According to him:

The Christofoel Blind Mission (CBM) is an NGO focused on a comprehensive community mental health programme. They are located at Jesus College, Otukpo. The programme is implemented by the Methodist Church and sponsored by CBM, an Australian-based NGO. The CBM is only in Benue State for now to implement the programme (B1).

The staff and the two trained nurses confirmed their existence and revealed the level of their commitment to what they set out to achieve.

\section{Memorandum of Understanding (MOU) with a Federal Training Institution}

A key strength employed by the NGO was the Memorandum of Understanding (MOU) they had with the School of Post-basic Psychiatric Nursing, Federal Neuro-psychiatric Hospital Kaduna to offer them at least five admission spaces for selected nurses every year to train these nurses for Benue State. This arrangement was confirmed by the staff of the NGO, the beneficiaries (the trained nurses) and even a health administrator in Kaduna State who volunteered the information when highlighting the absence of NGO for mental health in her own State (Kaduna).

\section{The Willingness of CBM-sponsored Nurses to work on the Mental Health Care Programme}

CBM trained nurses gave first-hand information on their readiness to work at the community level to provide community mental health services after their training. Their readiness was frustrated in diverse ways. As they put it:

I was trained for comprehensive community mental health services. After the training, they would employ us to work with the CBM in various LGAs where the sponsors (CBM) will take responsibility of our accommodation and transport, provide all the needed logistics, including drugs (C1).

After the training, we were to come down (from Kaduna, where the training took place) to the State to work with them. Benue State government could not employ us - me and three others. So I went back to Kaduna; I am now working in a private hospital and a children's hospital not even related to mental health services. My two other colleagues are also working in private hospitals here in Kaduna. We are waiting to be invited by (Benue) State government $(\mathrm{C} 2)$.

We were trained to go into LGAs twice a month to do the consultation, follow up, provide drugs (supplied by CBM), and if need be, call consultants from the State Teaching Hospital to see clients, then refer if necessary. We are also trained to give health talks, encourage early reporting of cases, teach 
women about mental health during antenatal and postnatal clinics for possible signs of mental health issues $(\mathrm{C} 1)$.

According to an opportunity to improve community mental health care was lost despite the availability of the resource. One of the trained nurses, working in Makurdi lamented, saying:

This aim of the training us by the NGO $(\mathrm{CBM})$ is not achieved because we are yet to hear from State if we will still be going to LGAs to work or not...presently some of us were absorbed into State University Teaching Hospital, awaiting when they will employ (us) for comprehensive community mental health programme for which we were trained (C1).

Another CBM sponsored now working outside the State also lamented during the interview, thus:

Benue State government could not employ us - me and three others. So I went back to Kaduna; I am now working in a private hospital and a children's hospital not even related to mental health services. My two other colleagues are also working in private hospitals here in Kaduna. We are waiting to be invited by (Benue) State government.

\section{Challenges faced by NGOs attempting to float MHS}

The challenges encountered were identified as:

\section{Getting Qualified and Interested Applicants}

An initial and major challenge for the training arrangement was how to get interested nurses who met admission requirements for training in Kaduna. The staff of the CBM explained the challenge on how the nurses for training are recruited and used after training, saying, "the CBM scouted for nurses who are qualified to be trained, but it was difficult to get such because of the O'L requirements".

Apart from getting the relevant qualifications to undertake the course, he also explained the issue of the qualified nurses that were interested to undertake the training. He said:

Apart from the challenges are getting suitably qualified (with O'L science credits), there are few interested Nurses who agreed to do the Mental Health training (C3).

He also added..." and there is lack of staff in the Benue State government generally."

\section{Government's Lack of Counterpart Fulfilment: Non-placement of the Trained Personnel}

Data from the health workers' survey indicate that about half of them (49.3\%) disagreed that any collaboration between governments and NGOs exist in providing mental healthcare services.

This result is further supported by narratives from the health coordinators and NGO in the study areas personnel. One area of such challenge is the lack of commitment to MOU by the State Government. PHC coordinators expressed the predicament of the government in not being able to honour the agreement with the NGO (the CBM) after the completion of training of the selected nurses. They agreed that an MOU was signed with the NGO, but the government is handicapped.

Well, the CBM also has an understanding with the (Benue) State government to employ these nurses after training, but the government cannot go against its policy which is an embargo on employment (B1).

The Benue state government cannot absorb them because of an embargo on employment (B2).

A PHC Director and the two nurses trained by the CBM also lamented this situation. One of the trained nurses sees it as "unbelievable" (B2). According to one PHC Director, the general embargo on employment has affected these nurses, but this is "regrettable...especially now that the mental health problems are too much in this State (sic)" (B1).

On what has been happening to those trained, he continued: 
well, some of them have complied (i.e., they reported back to the Government), some have not. Some of them are employed by other institutions; the remaining are still not engaged. But I learnt some of them got an appointment with the Teaching Hospital here in Makurdi. Some got jobs elsewhere; some staff of Local Governments went back to their stations (B1).

The Principal Investigator (PI) was able to get the narratives of two of the nurses trained by the NGO for their experiences. One of the trained nurses who now work in a hospital in one of the state capitals (Makurdi) said it was disgusting for the present government "to rubbish a rare offer from a foreign-based initiative like the CBM" $(\mathrm{C} 1)$.

Another one (a CBM sponsored nurse), working in a private hospital Kaduna after the Benue State government would not employ her after the training sponsored solely by CBM, narrated her experiences and disappointments:

The agreement was that the State will pay us, and the (CBM) will provide everything. But the State did not employ us. But up till now, we don't know how far, how they are doing. Presently, I am working in a private hospital, since they didn't call us, I came back to Kaduna. I now work in a private hospital here in Kaduna, a Paediatric Hospital for that matter. Benue State did not absorb us, me and three others in Kaduna here, all working private hospitals. We waited and waited for the State to employ us, but we had to look for work. We went to the Local government Service Commission several times, but they say there is an embargo; so, I came back to Kaduna. We are still waiting to be invited by the Benue State government $(\mathrm{C} 2)$.

\section{Lack of Staff to run the Comprehensive Community Mental Health Programme}

At the interview with a CBM staff at their office at Otukpo, Benue State, he narrated the challenges similar to those as narrated by one of the State Directors for Primary Health Care and
CBM sponsored trained nurses. But he added that lack staff remained the greatest challenge to providing the needed services. He reiterated the understanding the NGO had with the School of Post-basic Psychiatric Nursing, Federal Neuro-psychiatric Hospital Kaduna to train at least five selected nurses every year for Benue State. But according to him: "so far, the opportunities have not been utilised in the State” (C3).

The lack of staff has also been acknowledged by an official (i.e., State Director) of Primary Health Care and trainees as well to remain the crux of the challenges. Because of the lack of government commitment to MOU, a CBM trainee beneficiary simply said there is,

Still lack the staff to implement the Comprehensive Community Mental Health Programme even after the training of five of us and other staff; they could not have them on the programme $(\mathrm{C} 2)$.

\section{Discussion of Findings}

The study participants were both males and females from diverse geographic, religious, professional, and ethnic extractions to reflect the population spread of the study areas (three zones of northern).

The absence of mental health NGOs in virtually all the study areas except at one centre in Benue State and the complete absence of any in both Kaduna and Gombe States indicate the level of scarcity of community-based mental health services provided by NGOs [3,8]. This is in spite of the emphasis for such NGOs in addressing mental health issues [14, 11, 24, 25]. This is quite interesting in the viewing of the mirage of other NGOs working in many other areas of health care in these same states. In other areas of health care such as maternal, new-born and child health, NGOs have helped to reduce morbidities and mortalities in both developing and developed countries [13, 17, 18].

From our findings, there seems to be only a fragile and unsuccessful collaboration between 
the NGOs and one of the States since the unique opportunity presented by the NGO (i.e., CBM) was not explored for effective community-based mental health care. The existing NGOs identified in the study set out to do "community mobilization, sensitization and education are their main activities," a target set even by the Federal Ministry of Health Nigeria (2013) in the mission of National Policy for Mental Health Services Delivery Nigeria. This great mission statement fits the ideals of community-based mental health care into which any good collaboration would have impactful.

The role and desire of the government to make NGOs contribute to health care in terms of providing services and health advocacy is well established even in Nigeria and elsewhere $[14,15]$. The situation found in this study seems to fit into hitherto neglect and lack of deliberate policy on mental health ${ }^{7}$. The failed collaboration to meet the necessary manpower already built for community-based mental health care services could be offshoots of such policy lassitude. Mental health care seems to maintain its least priority in the government circle in Nigeria [1, 2, 3].

Our finding that mental health NGOs are difficult to come by in the study settings calls for a re-evaluation of government commitment to health care in general and mental health care in particular. Many other NGOs abound. Attempts to have stand-in NGOs provide appear unsupported, and in fact, an official in a State narrated that : NGOs for mental health are discouraged." Despite the calls by the authorities, the Federal Ministry of Health Nigeria, researchers, and WHO-fact sheet appealing for non-governmental organizations (NGOs) to come in and assist in the promotion of mental health care services [11, 16, 24].

In addition, studies in Nigeria and other parts of the world have revealed that mental health professionals are very scarce $[2,6,25]$. In our finding, trained specialists (the CBM-sponsored nurses), despite their willingness to use their expertise, their participation in mental health services for which they were trained was jettisoned. The failure of a government to employ these professionals as agreed because of the certain policy of the same government needs further empirical explanation.

This situation, the non-existence of NGOs in addition to the lack of formal mental health services in these study areas [3], leaves these communities with existing and looming mental health and psychological problems [26]. The indispensable roles of NGOs in promoting mental health and preventing mental health problems have been established in many health situations [27] They need to be prepared constantly in the face of current (and recurrent) socio-economic, political and health crises. Just recently, there have been calls in Nigeria and elsewhere for NGOs to come to the aid of health care services at the PHC level [27, 28]. This call is most urgent in the area of mental health services in the community in Nigeria, including the prevention of suicide [29] and capacity building for mental health care [30].

\section{Limitations of the Study}

This study is limited to only three states of the 19 states in northern Nigeria. Thus, the findings may not be generalizable to the entire region. In addition, this study adopted a manual analysis of the qualitative data because of our inability to acquire the proposed Nvivo software. However, the mixed methods used for this study and the quality of the participants as well as the content/thematic analyses were great strengths for the study.

\section{Conclusion}

Only an NGO focusing on community mental health services was found in one of the three States; even at that, the NGO primarily and initially focused on sight-saving (common eye problems) but only expanded its services to address some aspects of the stark community mental health services expected as part of its rehabilitative mission. The implications of this non-availability of any mental health NGOs in 
the study area is community mental health services such as psychoeducation, mental health first aid, and other primary mental health care that should have been powered by NGOs interventions will remain absent. Thus, wide treatment/intervention gaps remain. Avoidable mental health problems may arise, and the existing ones worsen.

\section{Recommendations}

Based on the findings of this study, it is recommended that NGOs in mental health should extend their activities to communities in the region while collaboration between government and NGOs need to be encouraged

\section{References}

[1] WHO Mental health and work: Impact, issues, and good practices. Mental Health Policy and Service Development. Nations for Mental Health, 2000: 1-77.

https://www.who.int/mental_health/media/en/712.pd f.

[2] WHO-AIMS Report. Mental Health System in Nigeria: A report of the assessment of the mental health system in Nigeria using the World Health Organization - Assessment Instrument for Mental Health Systems (WHO-AIMS), 2006. Ibadan, Nigeria.

[3] Anyebe, E.E., Olisah, V.O., Garba, S.N. and Amedu, M. The Current Status of Mental Health Services at the Primary Healthcare Level in Northern Nigeria. Administration and Policy in Mental Health and Mental Health Services Research: $2019 . \quad 1-9$ : available at: (https://link.springer.com/article/doi.org/10.1007/s1 0488-01900950-1) (First online: 2 July 2019).

[4] Punch Newspaper (Nov 13). 30\% of Nigerians Suffer Mental Illness - FG, 2018; available at http://saharareporters.com/2018/11/13/30-nigerianssuffer-mental-illness\%E2\%80\%93-fg. Accessed 31 March 2020.

[5] WHO Preventing suicide: A global imperative, 2014 Geneva: WHO. in area of Mental Health; Where such already exists, the government and partners should fulfil the respective parts of any pact to strength such collaborations, and to encourage for more support and coordination.

\section{Acknowledgements}

The Primary Health Agencies of the three States for their support and cooperation.

\section{Conflict of Interest}

The author declares that there is no Conflict of Interest.

[6] Okolo, O.S. and Iruo, L.A. Perceived determinants of Brain Drain among Mental Health Care Professionals in Specialist Health care Facilities in Benin City. International Journal of Innovative Science and Research Technology, 2021:6(1). 842-859.

[7] Adefuye, D. Budgetary Allocation to Health, Shame of a Nation, Association of Nigerian Physicians in America Blog, 2011: http://www.anpa.org/blog/2011/03/30/budgetaryallo cation-to-health-shame-of-a-nation accessed on March 20, 2012.

[8] Gureje, O. Challenges of Mental Health Care in Nigeria, 2015. A Webinar Internet Conference was held on $15^{\text {th }}$ December 2015.

[9] Makanjuola, R. "The Burden of Mental Health Problems," Mental Health Care in Nigeria, 2015. A Webinar Internet Conference in December 2015.

[10] Baqui, A.H.., Rosecrans, A.M., Williams, E.K., Agrawal, P.K., Ahmed, S. Darstadt, G.L., Kumar, V., Kiran, U., Panwar, D., Ahuja, R.C., Srivaslewa, V.K., Black, R.E., Santosham, M. NGO facilitation of a government community-based maternal and neonatal health programme in rural India: improvements in equity. Health Policy and Planning, 2008; 23(4):234-243. https://doi.org/10.1093/heapol/czn012.

[11]Herrman, H., Saxena, S and Moodie, R. (ed). Promoting Mental Health: Concepts, Emerging 
Evidence, Practice: A Report of the World Health Organization, Department of Mental Health and Substance Abuse in collaboration with the Victorian Health Promotion Foundation and The University of Melbourne, 2005: WHO Publication.

[12] Thara, R. and Patel, V. Role of nongovernmental organizations in mental health in India. Indian J Psychiatry,2010: 52(Suppl1): S389S395. doi: 10.4103/00195545.69276: 10.4103/00195545.69276.

[13] Patel P. Filling the Gap - An NGO's Role in Making Maternal Health More Acceptable in Rural Gujarat, 2016. A thesis presented to the University of Guelph, Ontario, Canada; available at: https://atrium.lib.uoguelph.ca/xmlui/bitstream/handl e/10214/10075/Patel_Pooja_20611_MA.pdf?seuenc e=1\&isAllowed=y Access March 31, 2020.

[14] Ahmed, I. NGO Works to Improve Maternal and Child Health in Northern Nigeria, 2009. (VOA news; November 01, 2009, 01:12pm). https://www.voanews.com/archive/ngoworksimprov e-maternal-and-child-health-northern-nigeria.

[15] Piotrowicz, M. and Cianciara, C. The Role of NGOs in the Social and the Health System; Przegl Epidemol, 2013. 67(1): 69-74: 151-155

[16]Premium Times (August 14). Nigeria health sector needs more meaningful foundations, NGOs Minister, 2013 at

https://www.premiumtimesng.com/news/142768nig eria-health-sector-needs-more-meaningful-

foundations-ngos-minister.html Accessed 31 March 2020.

[17] Mercer, A., Khan, M.H., Daulatuzzaman, M. and Reid, J. Effectiveness of an NGO primary health care programme in rural Bangladesh: evidence from the management information system. Health Policy and Planning, 2004; 19(4): 187-198.

[18] Okereke, E., Ishaku, S.M., Unumeri, G., Mohammed, B. and Ahonsi, B. Reducing maternal and newborn mortality in Nigeria-a qualitative study of stakeholders' perceptions about the performance of community health workers and the introduction of community midwifery at primary healthcare level. Human Resources for Health, 2019. 17:102.
[19] Jegede, A.S. "Mental Health." In African Culture and Health, enlarged edition. 2010. Ibadan: Bookwright Publishers (Nigeria).

[20]Lagos State Government. Mental Health Policy for Lagos State. 2020.

https://health.lagosstate.gov.ng/lagos-state-mentalhealth-programme Accessed 31st March 2020.

[21] Mental Health Foundation (MHF). Ambitious ideas \& brilliant implementation, 2020. Yaba Lagos Nigeria; https://mentalhealthnigeria.org/aboutcompany/ Accessed 31st March 2020

[22] Mentally Aware Nigeria Initiative. https://www.mhinnovation.net/organisations/mentall y-aware nigeria-initiative Accessed $31^{\text {st }}$ March 2020 [23] Amhaci. African Mental Health Awareness \& care Initiative, 2020. Nigeria.

[24]WHO Suicide: one person dies every 40 seconds,

2019; athttps://www.who.int/healthtopics/suicide\#tab=tab_ 1 Sept 10 Accessed March 22, 2020.Federal Ministry of Health Nigeria. National Policy for Mental Health Services Delivery Nigeria, 2013: Page $1-22$.

[26] Anyebe, E.E., Olisah V.O., Ejidokun, A. and Nuhu, F.T.; Mental Health Problems in Northern Nigerian Communities - An Exploratory Study. Journal of Physical and Life Sciences, 2017; a Publication of the National Open University of Nigeria Abuja available online at http://njpls.nou.edu.ng/njpls-journals.

[27] Nigeria Health Watch, NHW (July 9) NGOs Partner to Increase Accountability in the Delivery of PHC Services in Nigeria (Press Release ), 2019: https://nigeriahealthwatch.com/ngos-partner-toincrease-accountability-in-the-delivery-of-phcservices-in-nigeria/\#.XonELGB7Niu Accessed 31st March 2020.

[28] Story, W.T., LeBan, K, Altobelli, L.C., Gebrian, B., Hossain, J., Lewis, J., Morrow, M., Nielsen, J.N., Rosales, A., Rubardt M., Shanklin, D., and Weiss, J. Institutionalizing community-focused maternal, newborn, and child health strategies to strengthen health systems: A new framework for the Sustainable Development Goal era; Globalization and Health, 2017. 13:37. DOI 10.1186/s12992-0170259-z. 
[29] Bachmann S. Epidemiology of Suicide and the Psychiatric Perspective. Int. J. Environ. Res. Public Health, 2018;15:1425. doi:10.3390/ijerph15071425.

[30] Thornicroft, G., Cooper, S., Bortel, T.V., Kakuma, R., \& Lund, C. Capacity building in global mental health research. Harvard Review Psychiatry,
2012; 20, 13-24 retrieved from http://informahealthcare.com/doi/abs/10.3109/10673 229.2012.649117). 